\title{
Exosome-mediated microRNA-138 and vascular endothelial growth factor in endometriosis through inflammation and apoptosis via the nuclear factor- $\kappa B$ signaling pathway
}

\author{
AIFENG ZHANG ${ }^{1,2}$, GUOYUN WANG ${ }^{1}$, LIHUA JIA ${ }^{2}$, TAO SU $^{2}$ and LILI ZHANG ${ }^{3}$ \\ ${ }^{1}$ Department of Obstetrics and Gynecology, Qilu Hospital of Shandong University, Jinan, Shandong 250012; \\ ${ }^{2}$ Department of Obstetrics and Gynecology, Tongzhou Maternal and Child Health Hospital of Beijing, Beijing 101100; \\ ${ }^{3}$ Department of Obstetrics and Gynecology, Liaocheng People's Hospital, Liaocheng, Shandong 252000, P.R. China
}

Received October 1, 2017; Accepted October 19, 2018

DOI: $10.3892 / \mathrm{ijmm} .2018 .3980$

\begin{abstract}
Endometriosis (Ems) is a condition that refers to the ectopic implantation and growth of endometrial tissue outside the uterine cavity. The aim of the present study was to investigate the role of microRNA-138 (miR-138) in Ems and the possible underlying mechanism. Flow cytometry was measured CD11b level, cell proliferation was measured using MTT assay and lactate dehydrogenase (LDH) assays was analyzed using LDH activity kits. Cell apoptosis was measured using Annexin V-FITC/PI double staining apoptosis detection kit and DAPI assays. ELISA assay and western blot analysis were used to measure protein expression determination. It was first observed that miR-138 expression was markedly downregulated and the CD11b level was reduced in Ems mice compared with the control group. Subsequently, miR-138 expression was downregulated in the uterine endothelial cells co-cultured with THP-1 cells, which resulted in decreased apoptosis and increased inflammation in the uterine endothelial cells. By contrast, upregulation of miR-138 by mimic transfection increased the proliferation and reduced inflammation in uterine endothelial cells. In addition, in the co-culture of uterine endothelial and THP-1 cells, downregulation of miR-138 induced the expression of nuclear factor $(\mathrm{NF})-\kappa \mathrm{B}$ and vascular endothelial growth factor (VEGF) proteins in THP-1 cells. Furthermore, treatment with an NF- $\kappa \mathrm{B}$ inhibitor and downregulation of miR-138 in the co-culture of uterine endothelial and THP-1 cells reduced inflammation. VEGF inhibitor treatment and downregulation of miR-138 in this cell co-culture promoted the proliferation of uterine endothelial cells. These results suggested that uterine endothelial cells
\end{abstract}

Correspondence to: Dr Guoyun Wang, Department of Obstetrics and Gynecology, Qilu Hospital of Shandong University, 107 Wenhuaxi Road, Jinan, Shandong 250012, P.R. China

E-mail: wangguoy@sdu.edu.cn

Key words: endometriosis, microRNA-138, vascular endothelial growth factor, nuclear factor- $\kappa \mathrm{B}$ promoted miR-138 to induce exosome-mediated inflammation and apoptosis in Ems through the VEGF/NF- $\mathrm{B}$ signaling pathway.

\section{Introduction}

Cyclic variation of hormones leads to monthly shedding and regrowth of the uterine lining during menstruation. The ectopic endometrium results in the formation of pelvic cysts and adhesions (1). Endometriosis (Ems) is a painful disease that is easily recurrent and refractory due to its hormone-dependence (2). Therefore, treatment remains challenging for numerous patients and the clinicians in their professional field (3). Consequently, studying the pathogenesis of Ems will provide an insight into the disease development and create opportunities for formulating novel prevention strategies (1).

Ems is a common and frequently-occurring disease in young and middle-aged women, and its morbidity has displayed a marked increasing trend in recent years (4). It is a refractory disease characterized by extensive lesion, diversified morphology, invasion and recurrence (5). Although the pathogenesis of Ems remains unclear, the leading theory involves menstrual blood reflux (4). In addition, the eutopic endometrium determinism hypothesis is attracting extensive attention from scholars (6). Endometrial cells have to penetrate three layers, namely the peritoneal fluid, macrophages and peritoneal extracellular matrix (5), completing the three steps of adhesion, invasion and angiogenesis. Recently, the immunological mechanism of Ems has received increasing attention (6). Macrophages are multi-functional immune cells, and abnormality in their number and function may be one of the important reasons for Ems pathogenesis (3).

MicroRNAs (miRNAs) are a class of small endogenous RNA molecules with a length of 22-23 nucleotides and with a regulatory function, which has been identified in eukaryotes in recent years (7). miRNAs are extensively distributed in plants, animals and viruses, and can negatively regulate gene expression at the post-transcription level through complementary pairing with their target mRNAs (8). Therefore, they can induce mRNA degradation or translation inhibition. As 
important regulatory molecules, miRNAs participate in a series of important life processes, including virus defense, hematopoiesis, organ formation, cell proliferation and apoptosis, fat metabolism and tumorigenesis $(7,8)$.

Nuclear factor (NF)- $\kappa \mathrm{B}$ is an important nuclear transcription factor and exists in multiple cell types, and is involved in gene regulation in numerous physiological and pathological processes, including inflammation, immunity, cell proliferation, apoptosis and embryogenesis $(9,10)$. In addition, $\mathrm{NF}-\kappa \mathrm{B}$ is a universal transcription factor acting on multiple target genes (11), which includes the coding genes of cytokines, membrane receptors, membrane adhesion molecules, acute phase proteins, growth factors and transcription factors (10). Therefore, NF- $\mathrm{BB}$ activity is associated with biological processes such as cell growth and differentiation, inflammatory response, immune response and tumor growth. The NF- $\mathrm{NB}$-mediated signaling pathway can increase the expression of monocyte and T-cell selective chemokine RANTES, thus inducing Ems (11).

Vascular endothelial growth factor (VEGF) has also been reported to be a potential therapeutic target of Ems (12). VEGF, a member of the platelet-derived growth factor and VEGF family (12), is mainly expressed in the peripheral metanephron, armpit and jugular vein regions at the embryonic period (13). Research on Ems has revealed that VEGF serves an important role in this condition (13). Tang et al (14) reported that miR-138 protected against inflammation due to cerebral ischemia/reperfusion injury in rats. The present study aimed to investigate the role of miR-138 in Ems and the possible underlying mechanism.

\section{Materials and methods}

Experimental model. The present study was approved by the Institutional Animal Care and Use Committee of Qilu Hospital of Shandong University (Jinan, China), and all the procedures were performed according to the National Institutes of Health Guidelines for the Care and Use of Laboratory Animals. A total of 16 severe combined immunodeficiency mice $(20 \pm 2 \mathrm{~g}$; female; 8-9-weeks-old, $\mathrm{n}=8$ /every group) were purchased from Beijing Vital River Laboratory Animal Technology Co., Ltd. (Beijing, China) and housed in a light/dark cycle of 12-h under standard conditions $\left(22-24^{\circ} \mathrm{C}\right)$. Under anesthesia with $30 \mathrm{mg} / \mathrm{kg}$ of pentobarbital, endometriotic tissue was collected, cut into coarse fragments and suspended in PBS. Endometriotic cells $\left(1 \times 10^{6}\right.$ cells/1) were then implanted into the peritoneal cavity of the mice, and the mice were injected with $30 \mu \mathrm{g} / \mathrm{kg} /$ day estradiol benzoate (Shanghai Aladdin Biochemical Technology Co. Ltd., Shanghai, China) for 2 weeks. In control group, the mice were implanted with normal saline into the peritoneal cavity of the mice. Following the induction of endometriotic cells, mice were sacrificed under $30 \mathrm{mg} / \mathrm{kg}$ of pentobarbital.

Flow cytometry. Subsequent to sacrifice, $5 \mathrm{ml}$ PBS was injected into the mice by intraperitoneal injection. Following gentle massage for $10 \mathrm{~min}$, peritoneal fluid-containing cells was harvested and centrifuged at $1,000 \mathrm{x}$ g for $10 \mathrm{~min}$ at $4^{\circ} \mathrm{C}$, and the cell pellet was reconstituted in PBS with $2 \%$ fetal bovine serum (FBS; Thermo Fisher Scientific, Inc., Waltham, MA, USA). Cells were suspended in $100 \mu \mathrm{l}$ washing media and incubated with FITC-conjugated rat anti-mouse CD11b (cat. no. 553310; 1:100; BD Pharmingen; BD Biosciences, San Jose, CA, USA) at $4^{\circ} \mathrm{C}$ for $30 \mathrm{~min}$, followed by analysis using an LSRII flow cytometer (BD Biosciences).

Cell culture and treatments. ESCs were purchased from the Shanghai Cell Bank of the Chinese Academy of Sciences (Shanghai, China) and cultured in Dulbecco's modified Eagle's medium (DMEM)/F12 (Invitrogen; Thermo Fisher Scientific, Inc.) supplemented with 10\% FBS (Gibco; Thermo Fisher Scientific, Inc.), 20 nM HEPES (Sigma-Aldrich; Merck KGaA, Darmstadt, Germany) at $37^{\circ} \mathrm{C}$ and $5 \% \mathrm{CO}_{2}$. Next, ESCs were transfected according to the manufacturer's protocol with miR-138, anti-miR-138, NF- $\kappa$ B plasmids and VEGF plasmids and negative mimics $(50 \mathrm{nM})$ using Lipofectamine ${ }^{\circledR} 2000$ (Invitrogen; Thermo Fisher Scientific, Inc.) at $37^{\circ} \mathrm{C}$ and $5 \% \mathrm{CO}_{2}$ for $48 \mathrm{~h}$. Following $4 \mathrm{~h}$ of transfection, NF- $\kappa \mathrm{B}$ inhibitor (2 $\mu \mathrm{M}$ BAY 11-7085) or VEGF inhibitor ( $2 \mu \mathrm{M}$ Tanshinone IIA) was added into cell for $44 \mathrm{~h}$.

Transwell co-culture. Human leukemia monocytic cell line THP-1 cells $\left(1 \times 10^{6}\right.$ cells/well) were purchased from Shanghai cell bank of Chinese Academy of Sciences and seeded into 6-well plates and treated with $1 \mathrm{mM}$ phorbol-12-myristate-13-acetate. THP-1 is a leukemia monocytic cell line and is used to research inflammation. Co-culture with ESCs and THP-1 cells have been used as an inflammation model in endometriosis. ESCs transfected for $4 \mathrm{~h}$ were seeded $\left(1 \times 10^{6}\right.$ cells/well) onto polycarbonate Transwell inserts in the 6 -well plates (pore size, $0.4 \mu \mathrm{m}$; Costar; Corning, Inc., Corning, NY, USA). THP-1 cells were seeded at lower chambers in DMEM/F12 with $10 \%$ FBS. The co-culture of cells was incubated for $48 \mathrm{~h}$ at $37^{\circ} \mathrm{C}$ and $5 \% \mathrm{CO}_{2}$. Then, the cells from the co-culture were separated and then ESCs were collected by centrifugation at $500 \mathrm{x} g$ for $10 \mathrm{~min}$ for other experiments.

Cell proliferation and lactate dehydrogenase ( $L D H)$ assays. After $48 \mathrm{~h}$ of co-culture, MTT solution $(5 \mathrm{mg} / \mathrm{ml})$ was added to each well for $4 \mathrm{~h}$ at $37^{\circ} \mathrm{C}$. Next, the medium was removed, and $150 \mu \mathrm{l}$ DMSO was added to dissolve the purple crystals for $20 \mathrm{~min}$ at $37^{\circ} \mathrm{C}$. The absorbance of each well was measured at $490 \mathrm{~nm}$ to determine cell proliferation.

In addition, the LDH levels of cells were measured following $48 \mathrm{~h}$ of co-culture using LDH activity kits (cat. no. C0016; Beyotime Institute of Biotechnology, Nanjing, China) according to the manufacturer's protocol. The absorbance of each well was measured at $490 \mathrm{~nm}$ to determine the LDH activity.

Reverse transcription-quantitative polymerase chain reaction (RT-qPCR) analysis. Total RNA was isolated from the endometriosis tissues after surgery at 2 weeks or cells using $1 \mathrm{ml}$ TRIzol reagent (Invitrogen; Thermo Fisher Scientific, Inc.). RNA concentration was measured using an ELISA instrument. RNA concentration was measured using corresponding ELISA kits (Nanjing Jiancheng Bioengineering Institute, Nanjing, China) at optical density (OD) 260/OD280 nm. Total RNA was used to synthesize cDNA using a PrimeScript RT Reagent kit (Takara Biotechnology Co., Ltd., Dalian, China). qPCR was performed using a One Step SYBR PrimeScript 
PLUS RTPCT kit (Takara Biotechnology Co., Ltd.) and a Rotor-Gene 3000 Real-Time DNA analysis system (Corbett; Qiagen GmbH, Hilden, Germany). The PCR conditions were as follows: $95^{\circ} \mathrm{C}$ for $90 \mathrm{sec}$; 40 cycles for $95^{\circ} \mathrm{C}$ for $15 \mathrm{sec}$, $60^{\circ} \mathrm{C}$ for $30 \mathrm{sec}$ and $72^{\circ} \mathrm{C}$ for $30 \mathrm{sec}$. MicroRNA-138 primer 5'-CTCTATGCGTCTGTACAAG-3' and 5'-AGCUGGUGU UGUGAAUCAGGCCG-3'. miRNA expression was quantified using $2^{-\Delta \Delta \mathrm{Cq}}$ method (15).

Gene microarray hybridization. A total of $500 \mathrm{ng}$ total RNA was hybridized using G3 Mouse Whole Genome GE $860 \mathrm{~K}$ Microarray G4852A platform (Agilent Technologies, Inc., Santa Clara, CA, USA). Data were quantified using Agilent Feature Extraction Software (version A.10.7.3.1; Agilent Technologies, Inc.).

Apoptosis and DAPI assays. In order to determine the apoptosis rate, cells were washed with PBS and fixed with 4\% paraformaldehyde for $15 \mathrm{~min}$. Next, the cells were stained with the Annexin V-FITC/PI double staining apoptosis detection kit (BD Biosciences). The apoptosis rate was analyzed with an LSRII flow cytometer.

In order to stain the cell nucleus, cells were washed with PBS and fixed with $4 \%$ paraformaldehyde for $15 \mathrm{~min}$. Subsequently, cells were stained with DAPI assay (Beyotime Institute of Biotechnology) for $15 \mathrm{~min}$ in the dark. Cells were observed and images were captured using an X71 inverted microscope (Olympus Corporation, Tokyo, Japan).

ELISA assay and western blot analysis for protein expression determination. The THP-1 and ESCs from the co-culture were separated and cytokine levels were measured separately. The supernatant was collected at $48 \mathrm{~h}$ following centrifugation at $12,000 \mathrm{x} \mathrm{g}$ for $10 \mathrm{~min}$ at $4^{\circ} \mathrm{C}$. This was then used to measure the tumor necrosis factor $\alpha$ (TNF- $\alpha$; cat. no. H052), interleukin (IL)-1 $\beta$ (cat. no. H002), IL-6 (cat. no. H007) and IL-18 (cat. no. H015) levels using corresponding ELISA kits (Nanjing Jiancheng Biology Engineering Institute, Nanjing, China), according to the manufacturer's protocol.

For western blot analysis, cells were collected after centrifugation at $12,000 \times \mathrm{g}$ at $4^{\circ} \mathrm{C}$ and lysed with radioimmunoprecipitation assay lysis buffer (Beyotime Institute of Biotechnology). The protein concentration was measured using a BCA kit (Beyotime Institute of Biotechnology). Next, the isolated protein was subjected to 6-12\% SDS-PAGE and then transferred to a polyvinylidene difluoride membrane. The membrane was blocked with 5\% non-fat-milk in Tris-buffered saline/Tween 20 (TBST) for $1 \mathrm{~h}$ at $37^{\circ} \mathrm{C}$, following by incubation overnight at $4^{\circ} \mathrm{C}$ with VEGF (cat. no. sc-81670; 1:1,000; Santa Cruz Biotechnology, Inc., Dallas, TX, USA), NF-кB (cat. no. sc-71675; 1:1,000; Santa Cruz Biotechnology, Inc.), B-cell lymphoma 2-associated X protein (Bax; cat. no. sc-6236; 1:1,000; Santa Cruz Biotechnology, Inc.) and GAPDH (cat. no. sc-51631; 1:5,000; Santa Cruz Biotechnology, Inc.) primary antibodies. Subsequently, the membrane was washed with TBST for $30 \mathrm{~min}$ and incubated with a horseradish peroxidase-conjugated goat anti-rabbit IgG secondary antibody (cat. no. sc-2004; 1:5,000; Santa Cruz Biotechnology, Inc.) for $1 \mathrm{~h}$ at $37^{\circ} \mathrm{C}$. The protein signals were detected using a Super ECL Plus kit (KeyGen Biotech Co., Ltd., Nanjing, China), and
GAPDH served as the internal control. A protein blank was analyzed using Image Lab 3.0 (Bio-Rad Laboratories, Inc., Hercules, CA, USA).

Immunofluorescence. Cells were washed with PBS and fixed with $4 \%$ paraformaldehyde for $15 \mathrm{~min}$ at room temperature. Subsequently, cells were blocked with $5 \%$ bovine serum albumin (Beyotime Institute of Biotechnology) and $0.1 \%$ Tris-X100 in TBST for $1 \mathrm{~h}$ at $37^{\circ} \mathrm{C}$ and incubated with NF-кB (cat. no. sc-71675; 1:100; Santa Cruz Biotechnology, Inc.) overnight at $4^{\circ} \mathrm{C}$. Cells were washed with PBS and incubated with goat anti-rabbit IgG-CFL 555 (cat. no. sc-362272; 1:5,000; Santa Cruz Biotechnology, Inc.) for $1 \mathrm{~h}$ at $37^{\circ} \mathrm{C}$. Cells were washed with PBS and stained with DAPI assay for $15 \mathrm{~min}$ in darkness at room temperature. Cells were observed and images were captured using fluorescence X71 inverted microscope (Olympus Corporation).

Statistical analysis. Data are presented as the mean \pm standard deviation using SPSS 17.0 (SPSS, Inc., Chicago, IL, USA) and $\mathrm{P}<0.05$ was considered to indicate a statistically significant difference. One-way analysis of variance by Tukey's post hoc test was used to determine any statistically significant differences among groups.

\section{Results}

miR-138 expression and function in a rat model of Ems. First, a gene chip was used to measure the changes in different miRNAs in Ems, and it was observed that miR-138 expression was markedly downregulated in Ems rat compared with the normal control group (Fig. 1A). Next, RT-qPCR was used to analyzed the expression levels of miRNAs, and it was also observed that miR-138 expression was significantly downregulated in Ems rats as compared with the normal control group (Fig. 1B). Furthermore, it was observed that CD11b level was significantly reduced in the peritoneum of Ems rats, indicating reduced macrophages, compared with the control group (Fig. 1C and D).

miR-138 expression affects the growth of uterine endothelial cells in a co-culture with THP-1 cells. Uterine endothelial and THP-1 cells were co-culture to establish an in vitro model of Ems in the present study. miR-138 expression was also upregulated or downregulated in vitro model of uterine endothelial cells using miR-138 compared with the control group (Fig. 2A). Upregulation of miR-138 promoted the growth and inhibited the LDH activity of uterine endothelial cells, as well as suppressed caspase-3/9 levels and cell apoptosis (DAPI assay) in the co-culture of uterine endothelial and THP-1 cells (Fig. 2B-F). Anti-miR-138 mimics downregulated miR-138 expression in vitro model of uterine endothelial cells compared with the control group (Fig. 2G). Furthermore, downregulation of miR-138 reduced the growth and induced the LDH activity of uterine endothelial cells, while it increased the caspare-3/9 activity and cell apoptosis (DAPI assay; Fig. 2H-L).

miR-138 expression affects inflammation in a co-culture of uterine endothelial and THP-1 cells. Next, the study analyzed the changes in inflammation in the co-culture of 

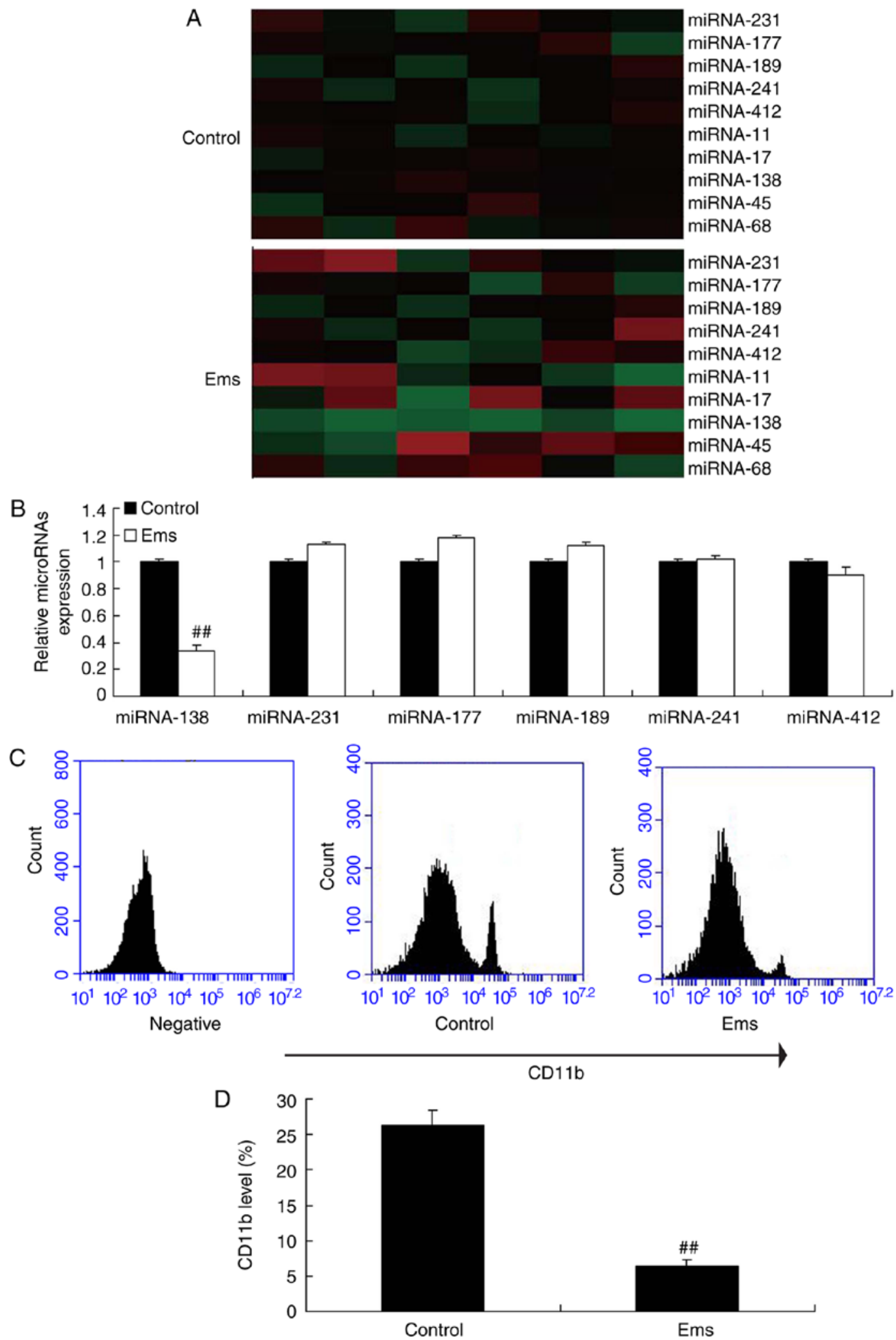

Figure 1. miR-138 expression and function in an animal model of Ems. (A) Gene chip analysis and (B) reverse transcription-quantitative polymerase chain reaction were used to examine miR-138 expression. (C) Flow cytometry (C and D) quantified results of CD11b levels analysis. ${ }^{\# \#} \mathrm{P}<0.01 \mathrm{vs}$. control group. Ems, endometriosis; miR, microRNA.

uterine endothelial and THP-1 cells. Upregulation of miR-138 expression inhibited TNF- $\alpha$, IL-1 $\beta$, IL- 6 and IL-18 levels compared with the control (Fig. 3A-D). Furthermore, downregulation of miR-138 expression also increased TNF- $\alpha$,
IL-1 $\beta$, IL-6 and IL-18 levels in THP-1 cells, compared with the control group (Fig. 3E-H). Therefore, the results revealed that upregulation of miR-138 expression reduced in uterine endothelial cells. 
A

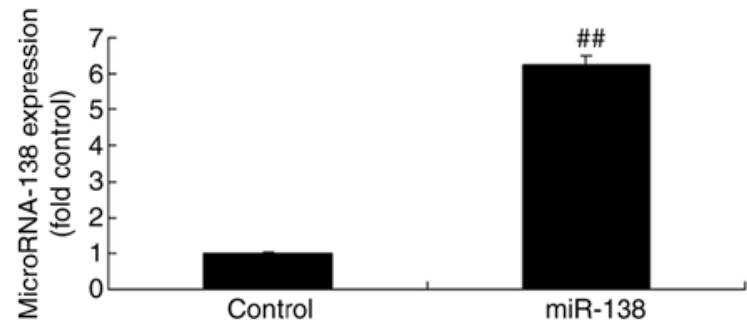

C

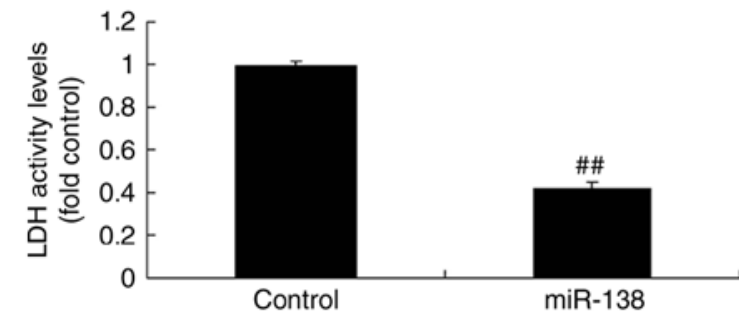

E

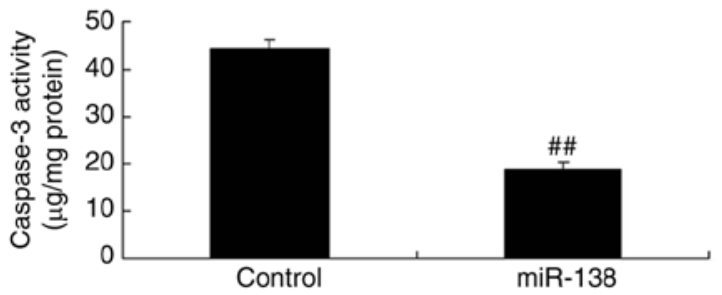

$\mathrm{G}$

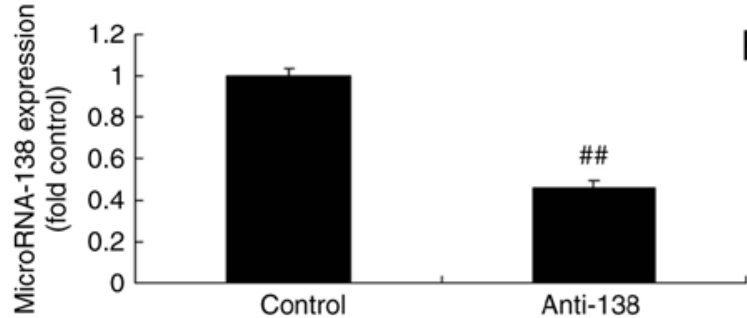

I
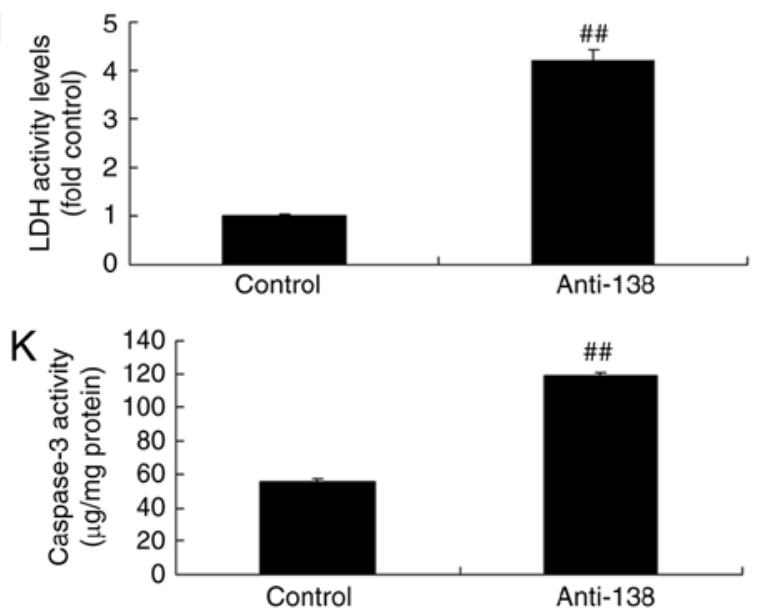

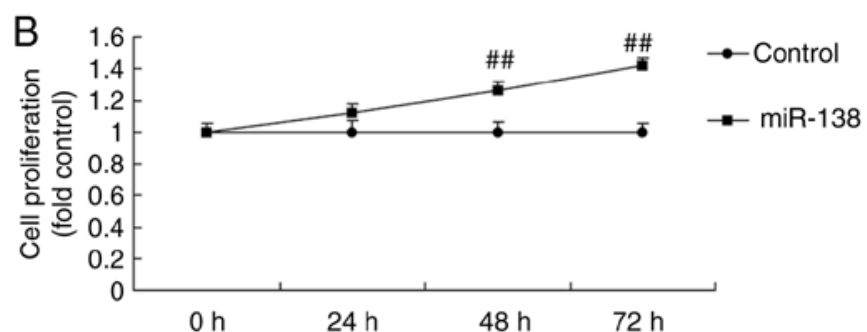

D

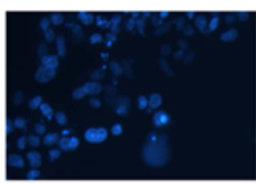

Control

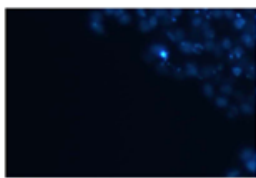

$\operatorname{miR}-138$
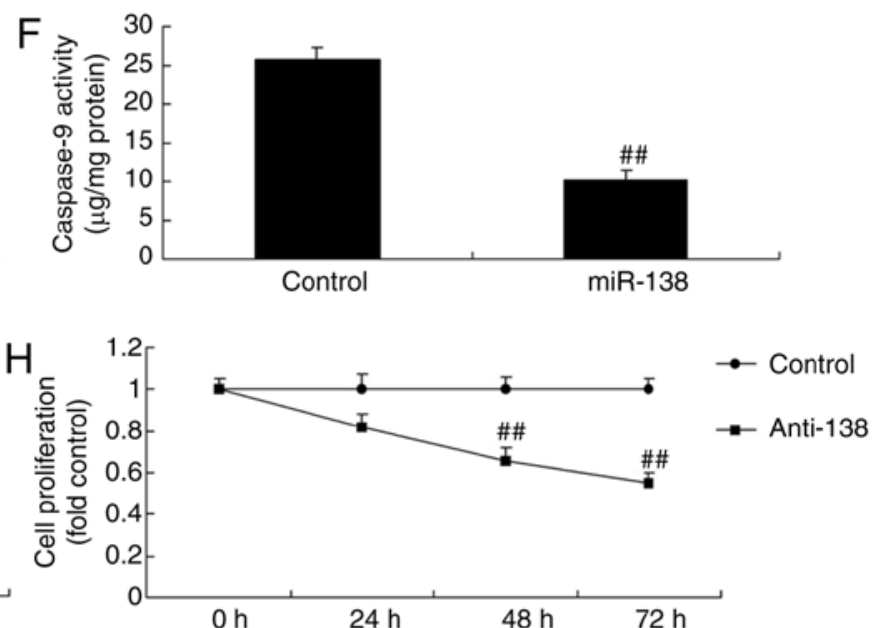

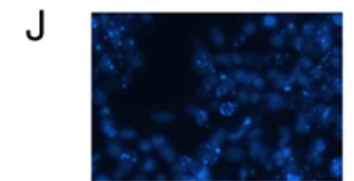

Control

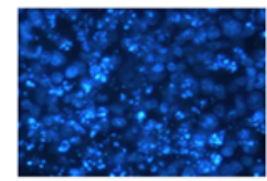

Anti-138

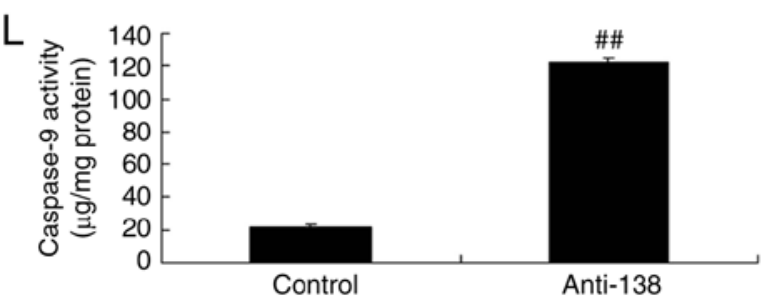

Figure 2. miR-138 expression affects the growth of uterine endothelial cells in a co-culture with THP-1 cells. (A) miR-138 expression, (B) cell growth, (C) LDH activity, (D) DAPI assay, (E) caspase-3 levels and (F) caspase-9 levels were examined following overexpression of miR-138 by transfection. (G) miR-138 expression, (H) cell growth, (I) LDH activity, (J) DAPI assay, (K) caspase-3 levels and (L) caspase-9 levels were examined following downregulation of miR-138. ${ }^{\# \#} \mathrm{P}<0.01$ vs. negative control group. miR, microRNA; LDH, lactate dehydrogenase; miR-138, overexpression group; anti-138, downregulation group.

miR-138 expression affects Ems in a co-culture of uterine endothelial and THP-1 cells through $N F-\kappa B$ and VEGF protein expression. The mechanism underlying the effects of miR-138 in Ems was determined. As shown in Fig. 4A and B, miR-138 was identified in the 3'-untranslated region of p65, and immunofluorescence assay revealed that upregulation of
miR-138 expression suppressed NF- $\kappa \mathrm{B}$ protein expression in THP-1 cells compared with the control cells. Subsequently, it was observed that upregulation of miR-138 expression suppressed Bax, NF- $\mathrm{KB}$ and VEGF protein expression levels in THP-1 cells. By contrast, downregulation of miR-138 suppressed Bax, NF- $\mathrm{kB}$ and VEGF protein expression levels 
A

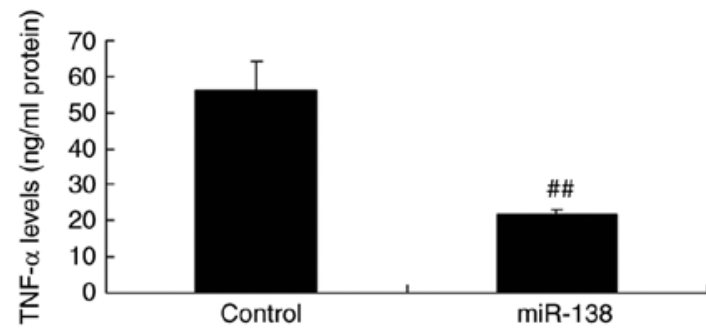

C

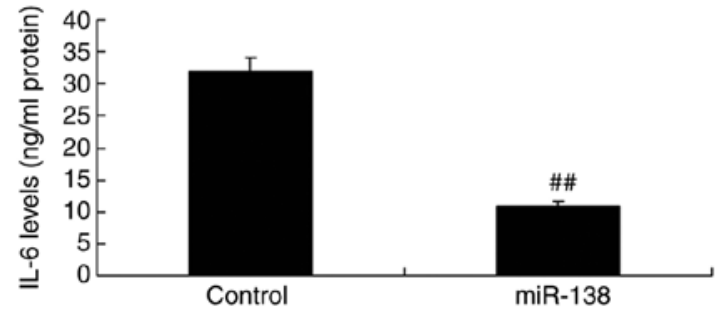

$\mathrm{E}$
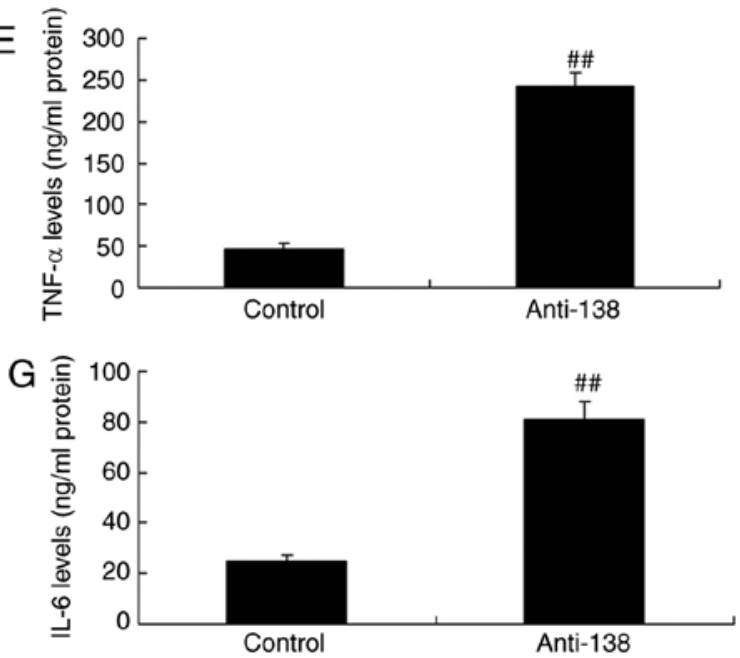

B
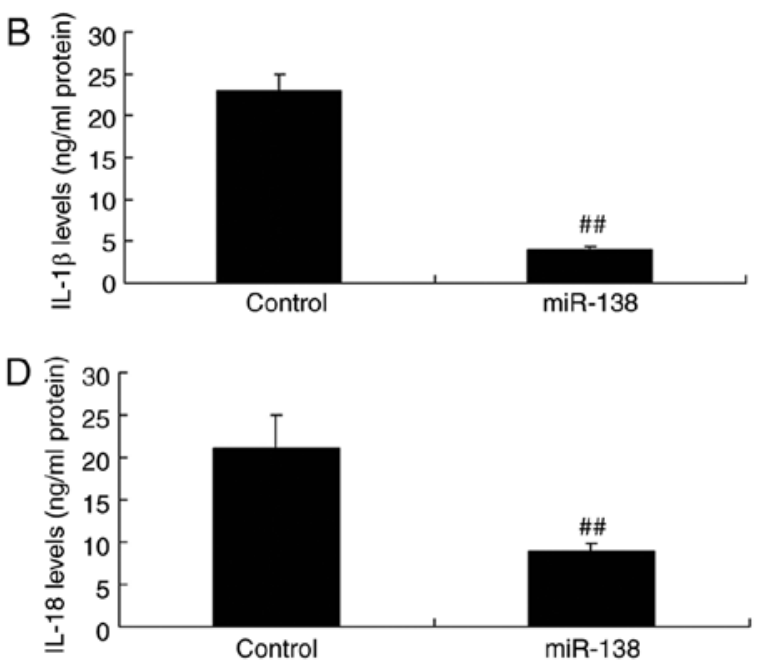

$F$
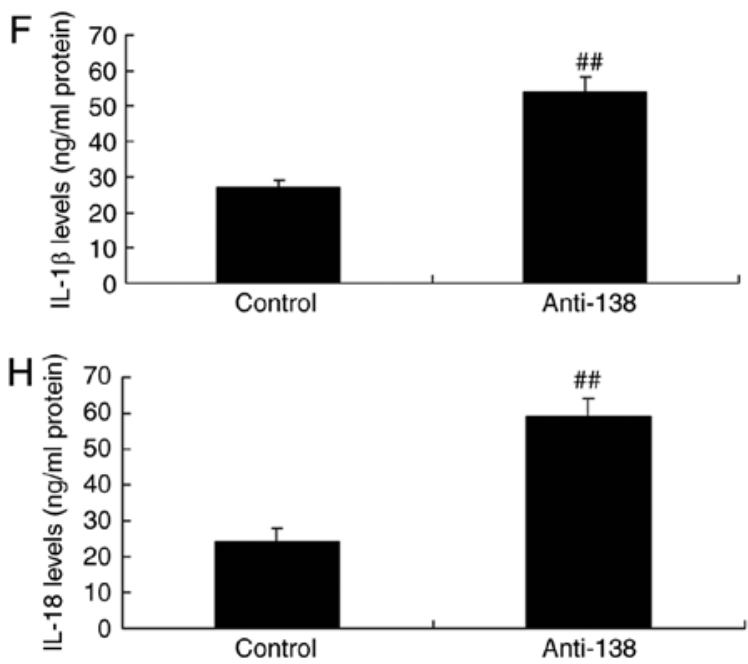

Figure 3. miR-138 expression affects inflammation in a co-culture of uterine endothelial and THP-1 cells. Overexpression of miR-138 expression inhibited (A) TNF- $\alpha$, (B) IL-1 $\beta$, (C) IL-6 and (D) IL-18 levels, while downregulation of miR-138 expression enhanced (E) TNF- $\alpha$, (F) IL-1 $\beta$, (G) IL-6 and (H) IL-18 levels. ${ }^{\# \#} \mathrm{P}<0.01$ vs. negative control group. miR, microRNA; TNF- $\alpha$, tumor necrosis factor $\alpha$; IL, interleukin; miR-138, overexpression group; anti-138, downregulation group.

in THP-1 cells in comparison with those in the control cells (Fig. 4C-J). These results demonstrated that miR-138 regulates $\mathrm{NF}-\kappa \mathrm{B}$ and VEGF protein expression in endometriosis.

Inhibition of $N F-\kappa B$ inhibits the effects of miR-138 downregulation on inflammation in co-culture with uterine endothelial cell and THP-1 cell. The function of NF- $\mathrm{NB}$ in the effects of miR-138 downregulation on inflammation and LDH activity of uterine endothelial cells in the co-culture with THP-1 cells was verified. As shown in Fig. 5A-D, addition of an NF- $\kappa \mathrm{B}$ inhibitor (2 $\mu \mathrm{M}$ BAY 11-7085) following miR-138 downregulation suppressed NF- $\mathrm{B}, \mathrm{VEGF}$ and Bax protein expression levels in THP-1 cells in the co-culture, as compared with the levels in the miR-138 downregulation alone group. In addition, Fig. 5E-H displays that the NF- $\kappa \mathrm{B}$ inhibitor treatment following miR-138 downregulation reduced TNF- $\alpha$, IL-1 $\beta$, IL-6 and IL-18 levels in the cytoplasm and THP-1 cells in the co-culture in comparison with those in the miR-138 downregulation alone group. Furthermore, NF- $\kappa \mathrm{B}$ inhibitor treatment following miR-138 downregulation increased the growth, and inhibited the LDH and caspase-3/9 activities of uterine endothelial cells in the co-culture, when compared with the miR-138 downregulation group (Fig. 6).

Inhibition of VEGF inhibits the effects of miR-138 downregulation on the $L D H$ activity of uterine endothelial cells in a co-culture with THP-1 cells. In order to involvement of VEGF in the effect of miR-138 on the LDH activity of uterine endothelial cells in a co-culture with THP-1 cells, a VEGF inhibitor ( $2 \mu \mathrm{M}$ Tanshinone IIA) was used. It was observed that VEGF and Bax protein expression levels of THP-1 cells in the co-culture were significantly suppressed when treated with VEGF inhibitor following miR-138 downregulation, as compared with the miR-138 downregulation alone group (Fig. 7A-C). In addition, VEGF inhibitor increased the growth, inhibited the LDH activity and decreased the caspase-3/9 activity of uterine endothelial cells in the co-culture following miR-138 downregulation, compared with those in cells with miR-138 downregulation alone (Fig. 7D-H).

Promotion of $N F-\kappa B$ inhibited the effects of miR-138 upregulation on inflammation in the co-culture of uterine 
A

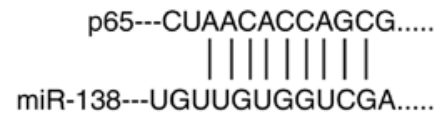

B
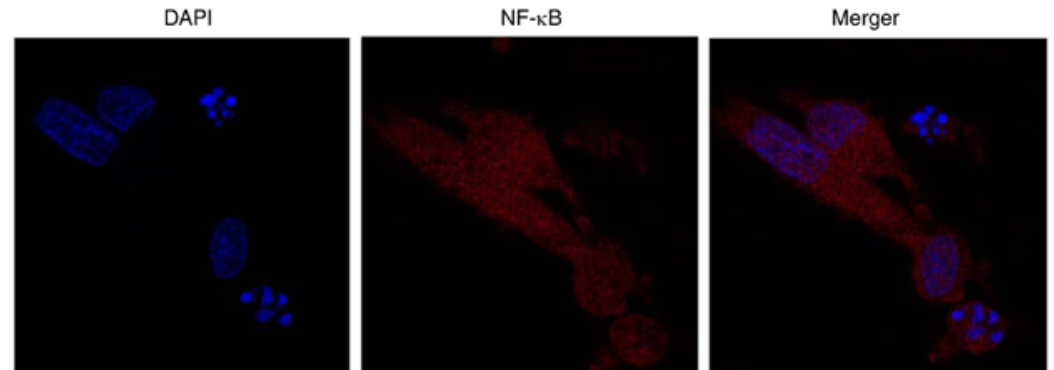

Control
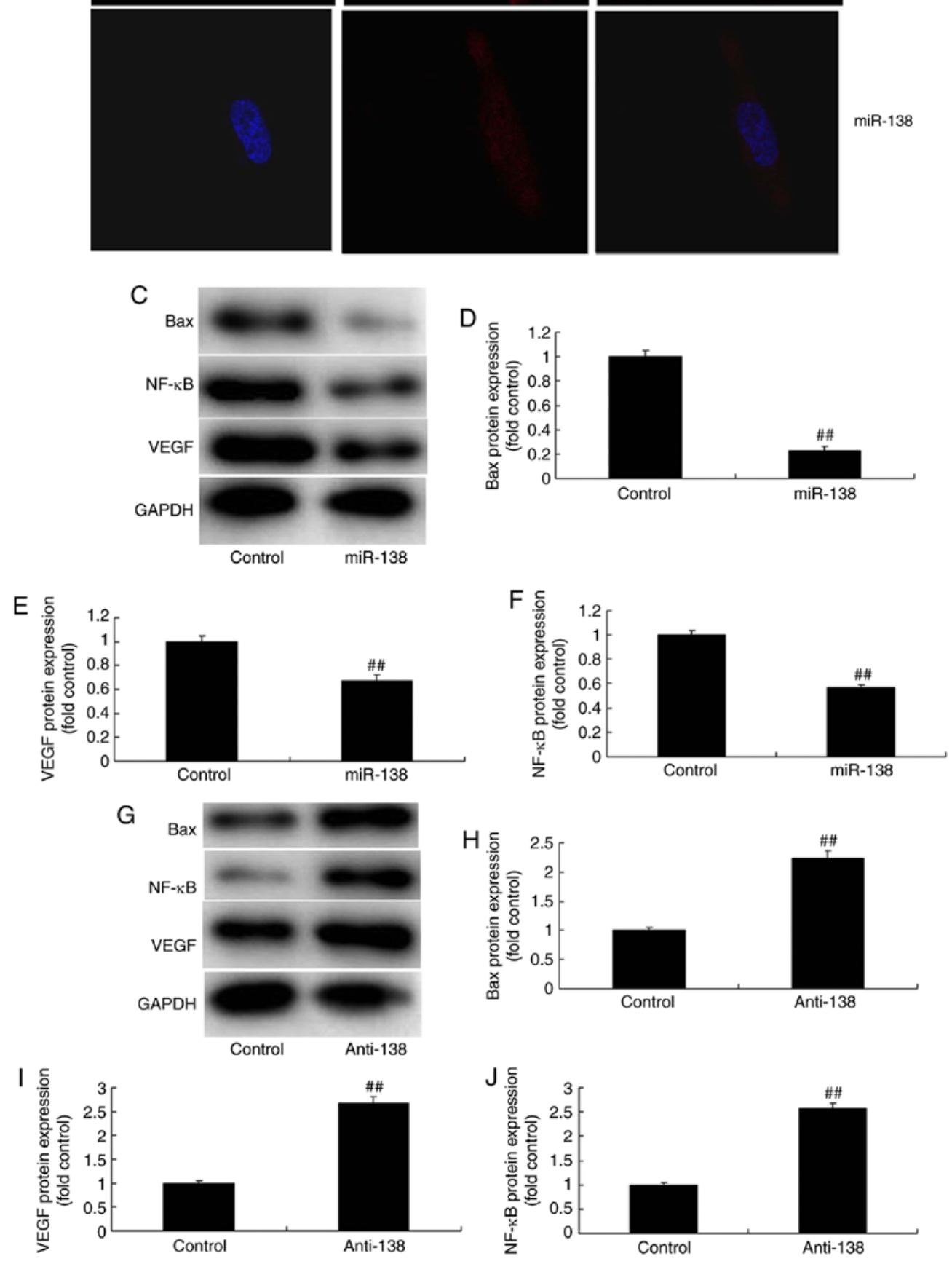

Figure 4. miR-138 expression affects endometriosis in a co-culture with THP-1 cells and ESCs through NF-kB expression. (A) miR-138 was identified in the 3'-untranslated region of $\mathrm{p} 65$, and (B) immunofluorescence revealed that NF-kB expression was suppressed in THP-1 cells (magnification, $\mathrm{x} 40$ ). (C) Western blot analysis showing that overexpression of miR-138 affects Bax, NF-кB and VEGF protein levels; quantified protein expression levels of (D) Bax, (E) VEGF and (F) NF-kB are shown. (G) Downregulation of miR-138 expression affects Bax, NF- $\mathrm{kB}$ and VEGF protein levels are determined by western blot assay; quantified results of (H) Bax, (I) VEGF and (J) NF- $\kappa B$ protein expression levels are shown. ${ }^{\# \#} \mathrm{P}<0.01$ vs. negative control group. miR, microRNA; Bax, B-cell lymphoma 2 -associated X protein; NF- $\mathrm{BB}$, nuclear factor- $\mathrm{kB}$; VEGF, vascular endothelial growth factor; miR-138, overexpression group; anti-138, downregulation group. 


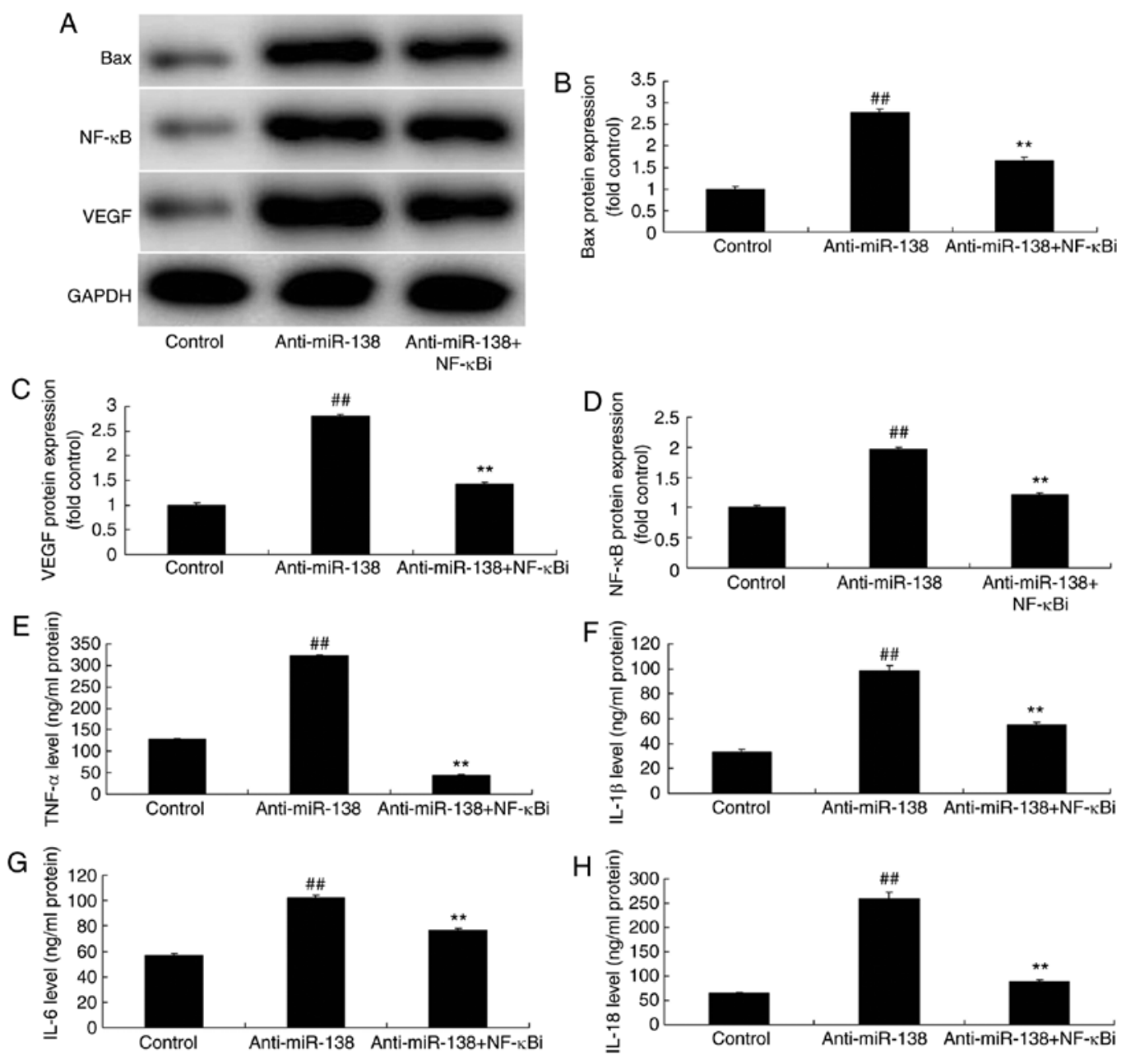

Figure 5. Inhibition of NF- $\mathrm{kB}$ inhibited the effects of miR-138 downregulation on inflammation in a co-culture of uterine endothelial and THP-1 cells. (A) Western blot assay, and quantified (B) Bax, (C) VEGF and (D) NF- $\mathrm{kB}$ protein expression levels. (E) TNF- $\alpha$, (F) IL-1 $\beta$, (G) IL-6 and (H) IL-18 levels are

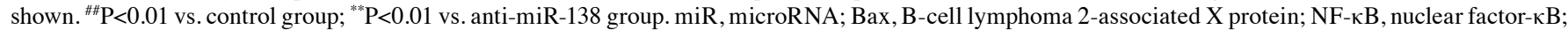

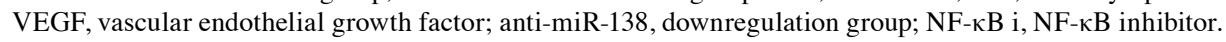
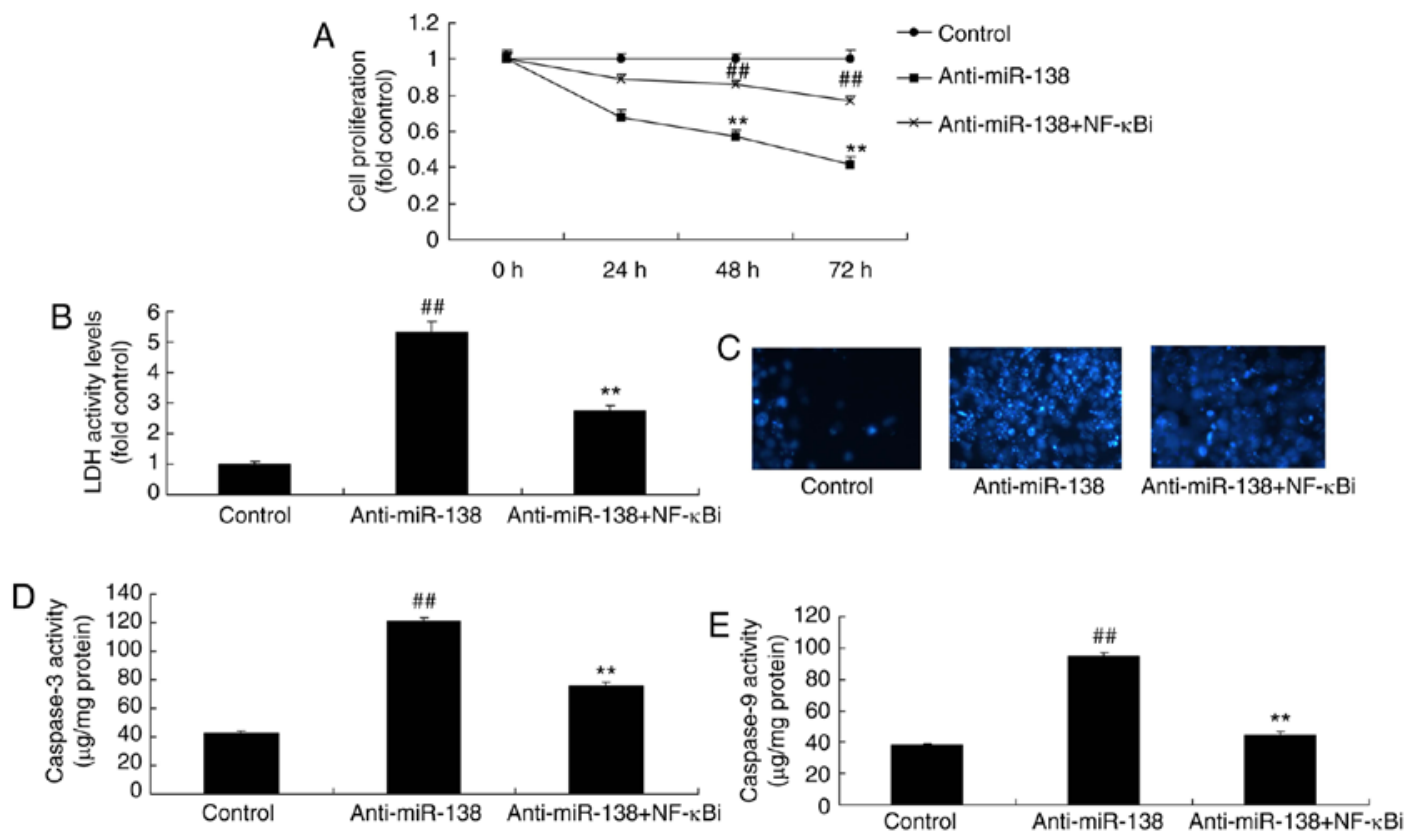

Figure 6. Inhibition of NF-кB inhibited the effects of miR-138 downregulation on the apoptosis of uterine endothelial cells in a co-culture with THP-1 cells. (A) Cell growth, (B) LDH activity, (C) DAPI assay, (D) caspase-3 levels and (E) caspase-9 levels. ${ }^{\# \#} \mathrm{P}<0.01$ vs. control group; ${ }^{* *} \mathrm{P}<0.01$ vs. anti-miR-138 group. $\mathrm{miR}$, microRNA; LDH, lactate dehydrogenase; anti-miR-138, downregulation group; NF- $\mathrm{kB} \mathrm{i}, \mathrm{NF}-\mathrm{kB}$ inhibitor. 

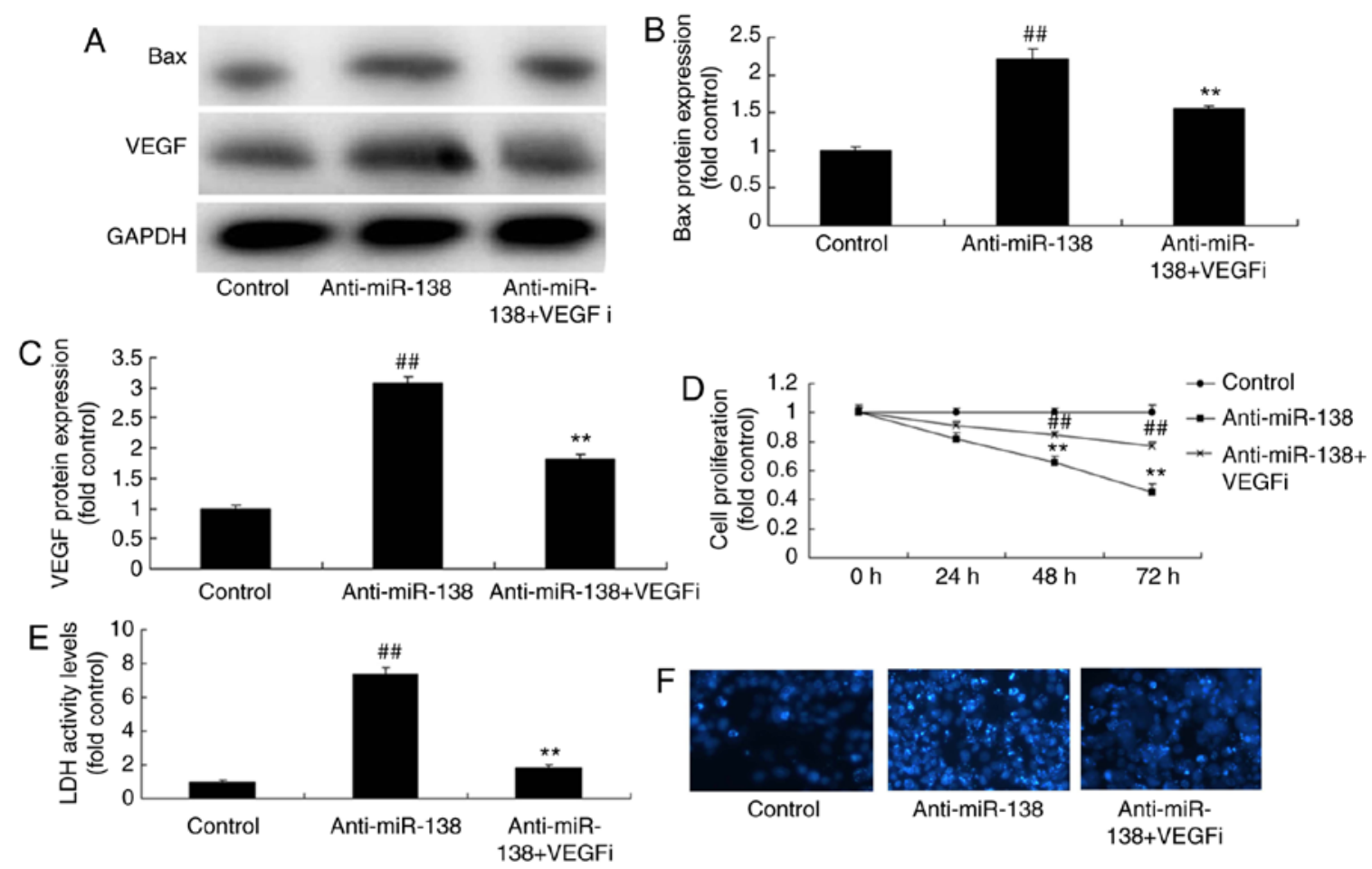
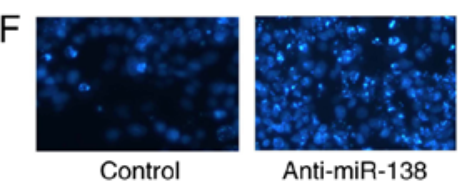

Anti-miR-138

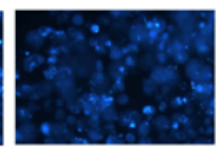

Anti-miR$138+$ VEGFi

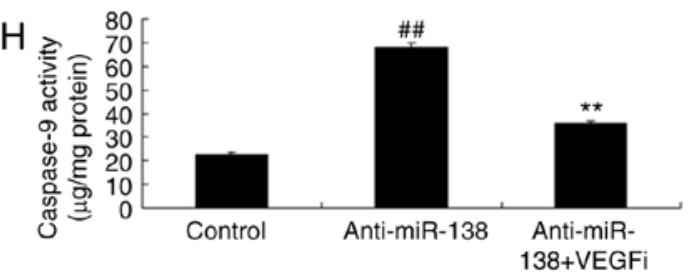

Figure 7. Inhibition of VEGF inhibited the effects of miR-138 downregulation on uterine endothelial cells in a co-culture with THP-1 cells. (A) Western blot analysis, and quantified levels of (B) Bax and (C) VEGF protein expression. (D) Cell growth, (E) LDH activity, (F) DAPI assay, (G) caspase-3 levels and $(\mathrm{H})$ caspase-9 levels. ${ }^{\# /} \mathrm{P}<0.01$ vs. control group; ${ }^{* *} \mathrm{P}<0.01$ vs. anti-miR-138 group. miR, microRNA; Bax, B-cell lymphoma 2 -associated $\mathrm{X}$ protein; VEGF, vascular endothelial growth factor; LDH, lactate dehydrogenase; anti-miR-138, downregulation group; VEGFi, VEGF inhibitor.

endothelial and THP-1 cells. The present study further analyzed the promotive effect of $\mathrm{NF}-\kappa \mathrm{B}$ on the effects of miR-138 upregulation in inflammation. As showed in Fig. 8A-D, $\mathrm{NF}-\kappa \mathrm{B}$ plasmid transfection following miR-138 upregulation induced NF- $\kappa \mathrm{B}, \mathrm{VEGF}$ and Bax protein expression in the co-culture of cells, as compared with the miR-138 upregulation alone group. Furthermore, NF- $\kappa \mathrm{B}$ activation increased TNF- $\alpha$, IL-1 $\beta$, IL- 6 and IL-18 levels were increased following miR-138 upregulation in the co-culture of cells in comparison with the miR-138 upregulation group cells (Fig. 8E-H). NF- $\kappa \mathrm{B}$ activation following miR-138 upregulation also decreased cell growth, increased LDH activity and caspase-3/9 activity in uterine endothelial cells of the co-culture, as compared with the miR-138 upregulation group (Fig. 9).

Promotion of VEGF inhibited the effects of miR-138 upregulation on the LDH activity of uterine endothelial cells in a co-culture with THP-1 cells. Next, VEGF plasmid transfection following miR-138 upregulation induced VEGF and Bax protein expression levels in the co-culture of cells, when compared with the miR-138 upregulation alone group (Fig. 10A-C). VEGF activation following miR-138 upregulation also increased the growth, and inhibited the LDH and caspase-3/9 activities of uterine endothelial cells in the co-culture, as compared with the miR-138 upregulation group (Fig. 10D-H). So, these results demonstrated that aberrant miR-138 expression may be the epigenetic mechanism underlying the actions of VEGF through the $\mathrm{NF}-\kappa \mathrm{B}$ signaling pathway (Fig. 11).

\section{Discussion}

Ems is a common benign disease in gynecology, which is induced by the growth of endometrial tissue outside the uterine cavity (16). The ovary is the most commonly involved organ, and the ectopic endometrial tissue is constituted by the endometrial gland and stroma, having functional activity (17). Invasive growth and repeated hemorrhage is locally observed in this condition. In addition, corresponding histological changes and clinical symptoms are observed (17). The condition generally manifests as chronic pelvic pain and dyspareunia, which may lead to irregular menstruation and even infertility (17). Cd11b $\mathrm{b}^{+}$ cells in the peritoneum are considered to be markers for the quantification of macrophages in Ems (18).

The results of the present study demonstrated that miR-138 expression was significantly downregulated in Ems rats compared with that in normal control, while the CD11b level was reduced in the peritoneum of Ems rats, demonstrating 

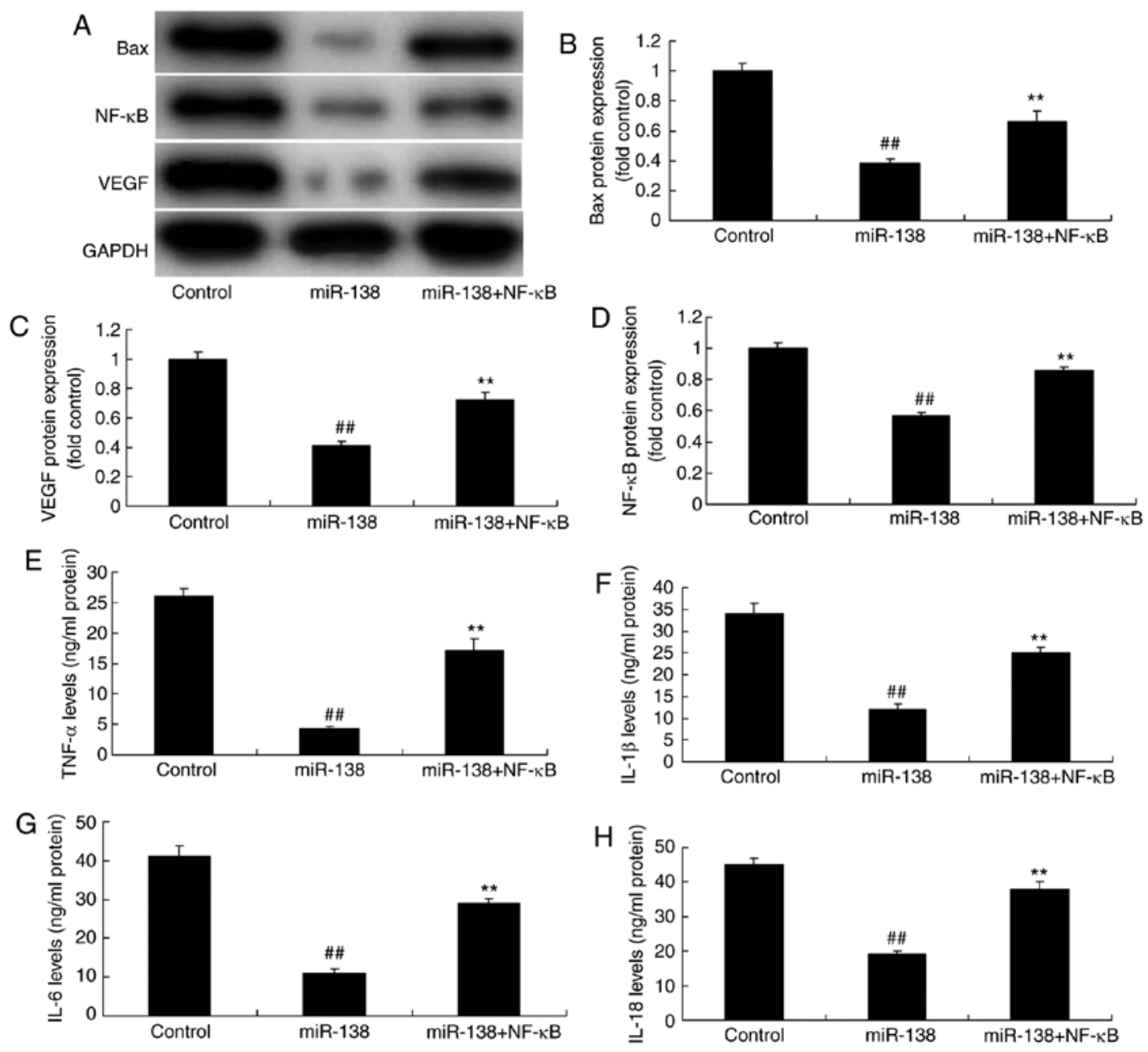

Figure 8. Promotion of NF-кB inhibited the effects of miR-138 upregulation on inflammation in a co-culture of uterine endothelial and THP-1 cells. (A) Western blot assay, and quantified (B) Bax, (C) VEGF and (D) NF- $\kappa B$ protein expression levels. (E) TNF- $\alpha$, (F) IL-1 $\beta$, (G) IL-6 and (H) IL-18 levels are shown. ${ }^{* \#} \mathrm{P}<0.01$

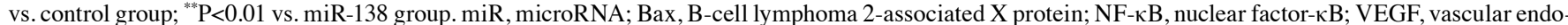
thelial growth factor; TNF- $\alpha$, tumor necrosis factor $\alpha$; IL, interleukin; miR-138, overexpression group; miR-138+NF-kB, overexpression of miR-138 and NF- $\mathrm{B}$.

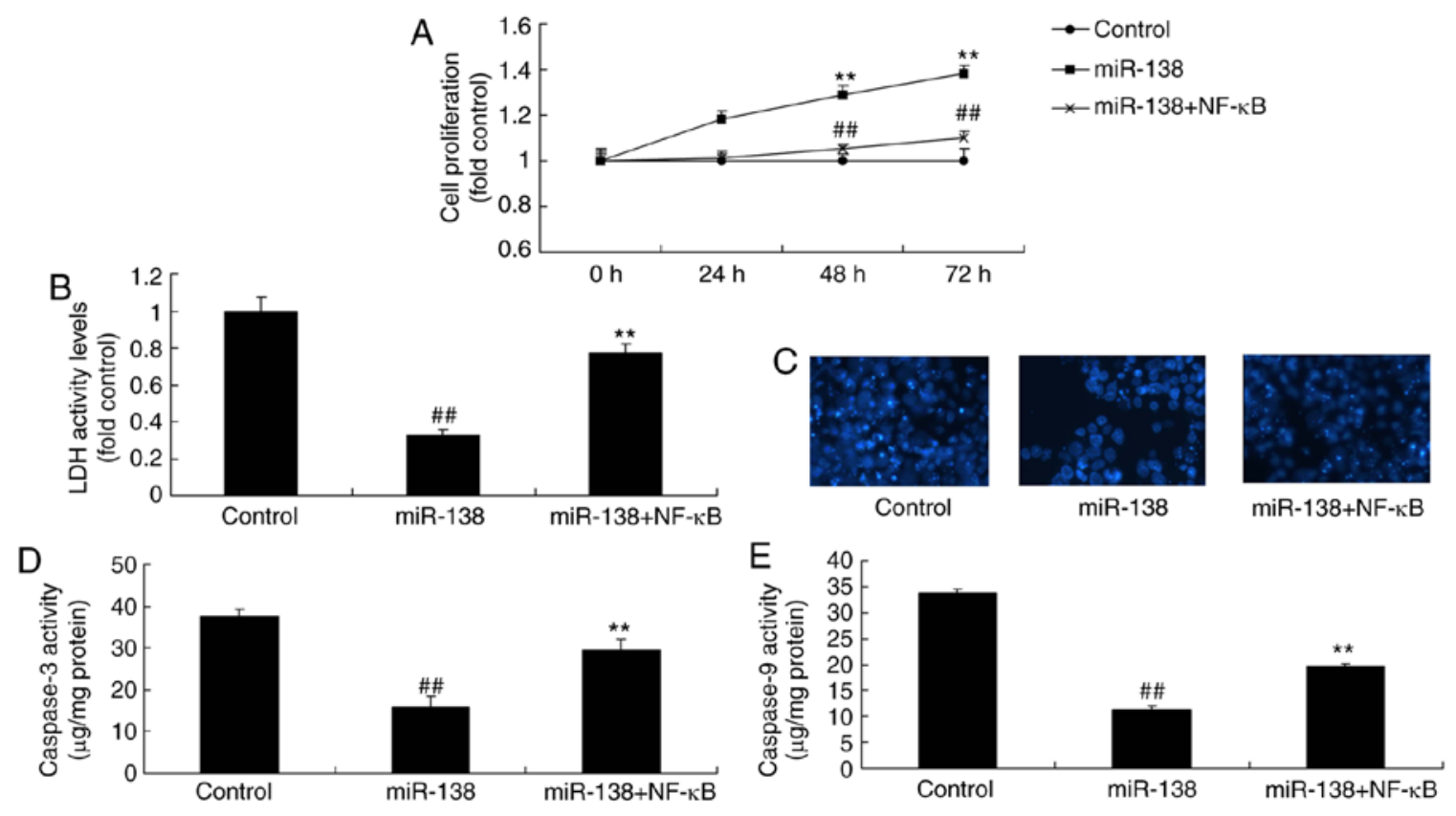

Figure 9. Promotion of NF- $\mathrm{kB}$ inhibited the effects of miR-138 upregulation on the apoptosis of uterine endothelial cells in a co-culture with THP-1 cells. (A) Cell growth, (B) LDH activity, (C) DAPI assay, (D) caspase-3 levels and (E) caspase-9 levels. ${ }^{\# \#} \mathrm{P}<0.01$ vs. control group; *"P $<0.01$ vs. miR-138 group. miR,

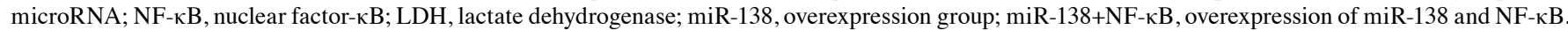



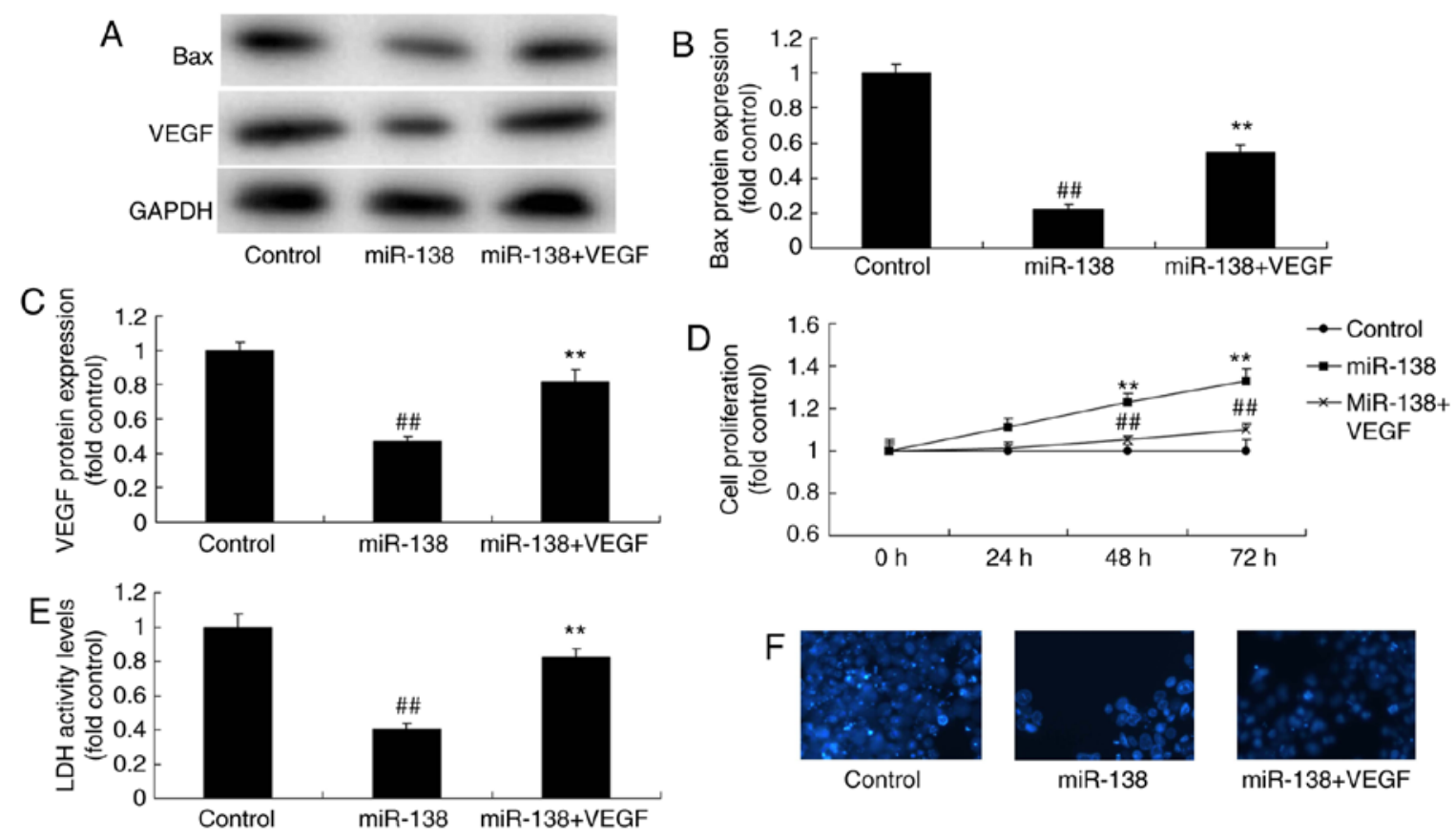

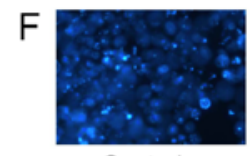

Control

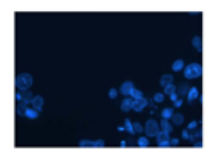

miR-138

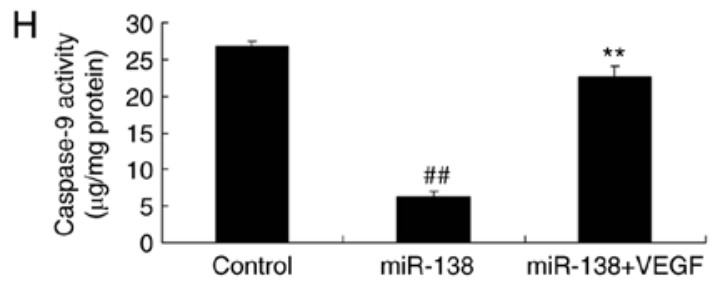

Figure 10. Promotion of VEGF inhibited the effects of miR-138 upregulation on LDH activity of uterine endothelial cells in a co-culture with THP-1 cells. (A) Western blot analysis, and quantified levels of (B) Bax and (C) VEGF protein expression. (D) Cell growth, (E) LDH activity, (F) DAPI assay, (G) caspase-3 levels and $(\mathrm{H})$ caspase-9 levels. ${ }^{* \#} \mathrm{P}<0.01$ vs. control group; ${ }^{* *} \mathrm{P}<0.01$ vs. miR-138 group. miR, microRNA; Bax, B-cell lymphoma 2-associated $\mathrm{X}$ protein; $\mathrm{VEGF,}$ vascular endothelial growth factor; LDH, lactate dehydrogenase; miR-138, overexpression group; miR-138+VEGF, overexpression of miR-138 and VEGF.

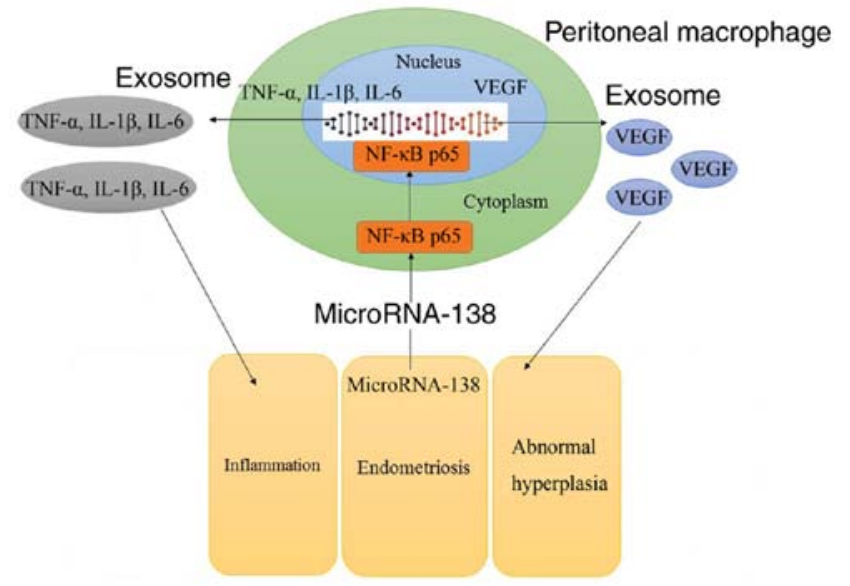

Figure 11. Exosome-mediated microRNA-138/VEGF in endometriosis through inflammation and apoptosis via the NF- $\kappa \mathrm{B}$ signaling pathway. Down-regulation of MicroRNA-138 induced inflammation through NF- $\mathrm{B}$ signaling pathway and promoted apoptosis through NF- $\mathrm{\kappa B} / \mathrm{VEGF}$ signaling pathway in endometriosis. miR, microRNA; VEGF, vascular endothelial growth factor; NF- $\kappa \mathrm{B}$, nuclear factor- $\kappa \mathrm{B}$; TNF- $\alpha$, tumor necrosis factor $\alpha$; IL, interleukin.

reduced number of macrophages in the peritoneum. In the current study, only an MTT assay was used to evaluate cell metabolism, which is a limitation in the evaluation of cellular proliferation. Future studies should use more methods to evaluate cellular metabolism, such as WST-1 and other tetrazolium reduction assays.

Macrophages act on multiple target cells through secreting multiple active factors (19). The mutual promotion or antagonism of these factors forms a complicated cell-cytokine network (19). Additionally, mutual promotion or antagonism of macrophage target can induce intraperitoneal inflammation and alter the abdominal microenvironment (20), as well as promote ectopic endometrial cell proliferation, invasion, growth and angiogenesis, thus participating in the genesis and development of Ems (20). Notably, macrophages are known to secrete ILs. The present study verified that TNF- $\alpha$, IL-1 $\beta$ and IL-6 concentrations in Ems peritoneal fluid were markedly higher in comparison with those in the normal control group (20). In the present study, downregulation of miR-138 expression was found to increase TNF- $\alpha$, IL- $1 \beta$, IL- 6 and IL-18 levels, decrease cell growth, promoted LDH activity and caspase-3/9 activity in Ems. Similarly, Tang et al (14) reported that of miR-138 protected against inflammation due to cerebral ischemia/reperfusion injury in rats.

$\mathrm{NF}-\mathrm{\kappa B}$ is an important transcription factor in cells, which exists in almost all eukaryotic cells (21). It serves a key role in regulating the inflammatory, immune stress responses, cell apoptosis and virus replication (21). In addition, NF- $\kappa$ B activity is associated with various biological processes, 
including cell growth and differentiation, inflammatory and immune response, and tumor growth. While NF- $\kappa \mathrm{B}$ is poorly expressed in normal endometrium (9), it is highly expressed in eutopic and ectopic endometrium (10). This indicates that the activation state of $\mathrm{NF}-\kappa \mathrm{B}$ is under the continuous regulation in normal endometrial tissue, whereas its excessive activation in eutopic and ectopic endometrial tissues is associated with the pathogenesis of Ems (10). The present study indicated that downregulation of miR-138 suppressed $N F-\kappa B$ and VEGF protein expression levels in THP-1 cells. A study by Gong et al (22) demonstrated that downregulation of miR-138 sustains $\mathrm{NF}-\kappa \mathrm{B}$ activation in esophageal squamous cell carcinoma. Sen et al (23) also reported that miR-138 regulates hypoxia-induced endothelial cell dysfunction by targeting VEGF.

It has been suggested that VEGF is a potent inducer of lymphangiogenesis, thus partly increasing the number of lymphatic vessels (24). As a result, it may be involved in the contact of invasive cancer cells with the lymphatic vessels. Furthermore, VEGF promotes malignant cancer cell invasion of the lymphatic vessel through elevating lymphatic vessel permeability and tumor stroma pressure, which further increases the metastatic ability of cancer cells (25). Research has suggested that VEGF expression in several cancer tissues is associated with the genesis and development of cancer (24). VEGF expression in multiple human primary malignant tumor tissues is also markedly correlated with regional lymph node metastasis, including in lung, laryngeal, gastric, prostate and esophageal cancer. The present study demonstrated that treatment with a NF- $\mathrm{BB}$ or VEGF inhibitor promoted cell proliferation, inhibited LDH activity and reduced inflammation in a co-culture of uterine endothelial and THP-1 cells following miR-138 downregulation. In a previous study, Wei et al (26) demonstrated that miR-138 expression enhanced the destruction of the cartilage tissues among osteoarthritis patients through p65. Similarly, the present study suggested that the miR-138/ VEGF axis may serve a significant role in the regulation of Ems.

In conclusion, miR-138 expression was observed to be significantly downregulated in Ems rats. The findings also suggested that aberrant miR-138 expression may be the epigenetic mechanism underlying the actions of VEGF through the $\mathrm{NF}-\kappa \mathrm{B}$ signaling pathway. Therefore, these observations may provide novel candidates that may serve as diagnostic biomarkers and therapeutic targets in Ems. The data of the present study will be further validated in our future studies on Ems.

\section{Acknowledgements}

Not applicable.

\section{Funding}

No funding was received.

\section{Availability of data and materials}

The analyzed data sets generated during the study are available from the corresponding author on reasonable request.

\section{Authors' contributions}

GW designed the experiment; AZ, LJ, TS and LZ performed the experiments; GW and AZ analyzed the data; GW wrote the manuscript. All authors read and approved the manuscript.

\section{Ethics approval and consent to participate}

The present study was approved by the Institutional Animal Care and Use Committee of Qilu Hospital of Shandong University (Jinan, China), and all the procedures were performed according to the National Institutes of Health Guidelines for the Care and Use of Laboratory Animals.

\section{Patient consent for publication}

Not applicable.

\section{Competing interests}

The authors declare that they have no competing interests.

\section{References}

1. Schwertner A, Conceicao Dos Santos CC, Costa GD, Deitos A, de Souza A, de Souza IC, Torres IL, da Cunha Filho JS and Caumo W: Efficacy of melatonin in the treatment of endometriosis: A phase II, randomized, double-blind, placebo-controlled trial. Pain 154: 874-881, 2013.

2. Hao Z and Huang S: E3 ubiquitin ligase Skp2 as an attractive target in cancer therapy. Front Biosci (Landmark Ed) 20: 474-490, 2015.

3. Campos Petean C, Ferriani RA, dos Reis RM, de Moura MD, Jordao AA Jr and Navarro PA: Lipid peroxidation and vitamin E in serum and follicular fluid of infertile women with peritoneal endometriosis submitted to controlled ovarian hyperstimulation: A pilot study. Fertil Steril 90: 2080-2085, 2008.

4. Barrueto FF, Audlin KM, Gallicchio L, Miller C, MacDonald R, Alonsozana E, Johnston M and Helzlsouer KJ: Sensitivity of narrow band imaging compared with white light imaging for the detection of endometriosis. J Minim Invasive Gynecol 22: 846-852, 2015.

5. Chen JM, Gao HY, Ding Y, Yuan X, Wang Q, Li Q and Jiang GH: Efficacy and safety investigation of Kuntai capsule for the add-back therapy of gonadotropin releasing hormone agonist administration to endometriosis patients: A randomized, double-blind, blank- and tibolone-controlled study. Chin Med J (Engl) 128: 427-432, 2015.

6. Ballester M, Santulli P, Bazot M, Coutant C, Rouzier R and Darai E: Preoperative evaluation of posterior deep-infiltrating endometriosis demonstrates a relationship with urinary dysfunction and parametrial involvement. J Minim Invasive Gynecol 18: 36-42, 2011.

7. Seifer BJ, Su D and Taylor HS: Circulating miRNAs in murine experimental endometriosis. Reprod Sci 24: 376-381, 2017.

8. Wang WT, Sun YM, Huang W, He B, Zhao YN and Chen YQ: Genome-wide long non-coding RNA analysis identified circulating LncRNAs as novel Non-invasive diagnostic biomarkers for gynecological disease. Sci Rep 6: 23343, 2016.

9. Zhu F, Liu M, Pan Y, Wang X and Chen Y: Small hairpin RNA targeting inhibition of NF- $\mathrm{KB}$ gene in endometriosis therapy of Macaca fascicularis. Zhonghua Fu Chan Ke Za Zhi 50: 48-53, 2015 (In Chinese).

10. Celik O, Ersahin A, Acet M, Celik N, Baykus Y, Deniz R, Ozerol E and Ozerol I: Disulfiram, as a candidate NF- $\mathrm{kB}$ and proteasome inhibitor, prevents endometriotic implant growing in a rat model of endometriosis. Eur Rev Med Pharmacol Sci 20: 4380-4389, 2016

11. Alvarado-Diaz CP, Núñez MT, Devoto L and González-Ramos R: Iron overload-modulated nuclear factor kappa-B activation in human endometrial stromal cells as a mechanism postulated in endometriosis pathogenesis. Fertil Steril 103: 439-447, 2015. 
12. Fujii EY, Nakayama $M$ and Nakagawa A: Concentrations of receptor for advanced glycation end products, VEGF and CML in plasma, follicular fluid, and peritoneal fluid in women with and without endometriosis. Reprod Sci 15: 1066-1074, 2008.

13. Dziunycz P, Milewski L, Radomski D, Barcz E, Kamiński P, Roszkowski PI and Malejczyk J: Elevated ghrelin levels in the peritoneal fluid of patients with endometriosis: Associations with vascular endothelial growth factor (VEGF) and inflammatory cytokines. Fertil Steril 92: 1844-1849, 2009.

14. Tang XJ, Yang MH, Cao G, Lu JT, Luo J, Dai LJ, Huang KM and Zhang LI: Protective effect of microRNA-138 against cerebral ischemia/reperfusion injury in rats. Exp Ther Med 11: 1045-1050, 2016

15. Livak KJ and Schmittgen TD: Analysis of relative gene expression data using real-time quantitative PCR and the 2(-Delta Delta C(T)) method. Methods 25: 402-408, 2001.

16. Takaesu Y, Nishi H, Kojima J, Sasaki T, Nagamitsu Y, Kato R and Isaka K: Dienogest compared with gonadotropin-releasing hormone agonist after conservative surgery for endometriosis. J Obstet Gynaecol Res 42: 1152-1158, 2016.

17. Leone Roberti Maggiore U, Remorgida V, Scala C, Tafi E, Venturini PL and Ferrero S: Desogestrel-only contraceptive pill versus sequential contraceptive vaginal ring in the treatment of rectovaginal endometriosis infiltrating the rectum: A prospective open-label comparative study. Acta Obstet Gynecol Scand 93: 239-247, 2014.

18. Wieser F, Wu J, Shen Z, Taylor RN and Sidell N: Retinoic acid suppresses growth of lesions, inhibits peritoneal cytokine secretion, and promotes macrophage differentiation in an immunocompetent mouse model of endometriosis. Fertil Steril 97: $1430-1437,2012$

19. Cakmak H, Seval-Celik Y, Arlier S, Guzeloglu-Kayisli O, Schatz F, Arici A and Kayisli UA: p38 Mitogen-activated protein kinase is involved in the pathogenesis of endometriosis by modulating inflammation, but not cell survival. Reprod Sci 25: 587-597, 2018.
20. Grandi G, Mueller MD, Bersinger NA, Facchinetti $F$ and McKinnon BD: The association between progestins, nuclear receptors expression and inflammation in endometrial stromal cells from women with endometriosis. Gynecol Endocrinol 33: 712-715, 2017.

21. Celik O, Celik E, Turkcuoglu I, Yilmaz E, Ulas M, Simsek Y, Karaer A, Celik N, Aydin NE, Ozerol I and Unlu C: Surgical removal of endometrioma decreases the NF- $\mathrm{BB} 1(\mathrm{p} 50 / 105)$ and $\mathrm{NF}-\kappa \mathrm{B}$ p65 (Rel A) expression in the eutopic endometrium during the implantation window. Reprod Sci 20: 762-770, 2013.

22. Gong H, Song L, Lin C, Liu A, Lin X, Wu J, Li M and Li J. Downregulation of miR-138 sustains NF- $\kappa \mathrm{B}$ activation and promotes lipid raft formation in esophageal squamous cell carcinoma. Clin Cancer Res 19: 1083-1093, 2013.

23. Sen A, Ren S, Lerchenmuller C, Sun J, Weiss N, Most P and Peppel K: MicroRNA-138 regulates hypoxia-induced endothelial cell dysfunction by targeting S100A1.PLoS One 8: e78684, 2013.

24. Makabe T, Koga K, Miyashita M, Takeuchi A, Sue F, Taguchi A, Urata Y, Izumi G, Takamura M, Harada M, et al: Drospirenone reduces inflammatory cytokines, vascular endothelial growth factor (VEGF) and nerve growth factor (NGF) expression in human endometriotic stromal cells. J Reprod Immunol 119: 44-48, 2017.

25. Rein DT, Schmidt T, Bauerschmitz G, Hampl M, Beyer IM, Paupoo AA, Curiel DT and Breidenbach M: Treatment of endometriosis with a VEGF-targeted conditionally replicative adenovirus. Fertil Steril 93: 2687-2694, 2010.

26. Wei ZJ, Liu J and Qin J: miR-138 suppressed the progression of osteoarthritis mainly through targeting p65. Eur Rev Med Pharmacol Sci 21: 2177-2184, 2017.

This work is licensed under a Creative Commons Attribution-NonCommercial-NoDerivatives 4.0 International (CC BY-NC-ND 4.0) License. 